\title{
Real-Time Detection of Polymerase Activity Using Supercritical Angle Fluorescence
}

\author{
Alexander Krieg, ${ }^{1}$ Thomas Ruckstuhl, ${ }^{1}$ Stephan Laib, ${ }^{1}$ and Stefan Seeger ${ }^{1,2}$
}

Received September 9, 2003; accepted September 30, 2003

\begin{abstract}
We investigated the incorporation efficiencies of different fluorescently labelled dNTPs with polymerases by complementary strand synthesis. For this reason single stranded DNA was immobilized on a coverslip and the increase of fluorescence due to the synthesis of the corresponding strand with tagged dNTPs was detected with a supercritical angle fluorescence biosensor in real-time. By comparison of the observed signal intensities it was possible to conclude that the system Cy5-dCTPKlenow (exonuclease free) fragment gives the best incorporation yield of the investigated enzymes and dNTPs.
\end{abstract}

KEY WORDS: Biosensors; fluorescence dyes; polymerase; primer elongation.

\section{INTRODUCTION}

Polymerases are of great importance for multiplying DNA in vivo as well as in vitro. Enzymatic double strand synthesis is used in many different applications of modern biology, such as polymerase chain reaction (PCR) [1], DNA sequencing [2-5] or gene expression [6]. Evolution has created a large variety of polymerases with different features [7]. One prominent example is the Taq-polymerase with working temperatures up to $80^{\circ} \mathrm{C}$, which plays the fundamental role in PCR.

To sequence DNA with fluorescent methods enzymes are desired, that are able to synthesize double stranded DNA (dsDNA) containing dye labelled bases. Due to steric hindrances the incorporation of dye-dNTPs turned out to be quite inefficient with most polymerases. In any case the enzymatic activity is affected by the label, nevertheless some species have been found to deliver reasonable incorporation yields under certain conditions $[8,9]$.

In the present paper we studied surface bound dsDNA synthesis in order to optimize the incorporation efficiency

\footnotetext{
${ }^{1}$ Physikalisch-Chemisches Institut, Universität Zürich, Winterthurerstr. 190, 8057 Zürich, Switzerland.

${ }^{2}$ To whom correspondence should be addressed. E-mail: sseeger@ pci.unizh.ch
}

of Cy5 fluorophores. We used three enzymes known to cope with the markers, T7-polymerase, Klenow-fragment and Cyscribe reverse transcriptase, varied the reaction temperature and compared the yield of both commercially available Cy5-dNTPs, i.e. Cy5-dCTP and Cy5-dUTP (ribonucleic acid pendant of dTTP).

The incorporation of Cy5 into the surface bound complexes was detected by measuring the supercritical angle fluorescence (SAF) emission in real time with a biosensor of custom design [10].

\section{MATERIALS AND METHODS}

Preparation of poly-L-lysine (PLL) coated coverslips: The substrates (Menzel-Glaser, Germany) were cleaned in an ultrasonic bath in ethanol solution $(70 \%, 30 \mathrm{~min})$, in aqueous $\mathrm{NaOH} /$ ethanol $(25 \mathrm{~g}$ $\mathrm{NaOH}$ in $250 \mathrm{~mL} 60 \%$ ethanol, $2 \mathrm{hr}$ ) and rinsed with bidistilled water. Subsequently they were prepared in a PLL-solution $(0.01 \% \mathrm{w} / \mathrm{v}$, Sigma Diagnostics, USA in PBS buffer, pH 7.48 Fluka, Switzerland ) for $1 \mathrm{hr}$ and dried at $45^{\circ} \mathrm{C}$ in a vacuum oven. Then they were modified in glutaraldehyde solution $(20 \mathrm{~mL}, 2.5 \%$ Fluka, Switzerland) for $1 \mathrm{hr}$ and rinsed with bidistilled water. 


\section{Primer Annealing and Coupling} of Aminated ssDNA to the Glass

For the comparison of the incorporation efficiencies of the enzymes 100 nucleotides (nt) long ssDNA containing 15 guanine bases was chosen, which provides incorporation for $15 \mathrm{Cy} 5$ tagged dCTPs, as for the comparison of the incorporation of the two bases (dCTP and dUTP) $55 \mathrm{nt}$ long ssDNA containing three guanine respectively three adenine bases were in use (ssDNA purchased by Microsynth Switzerland). After primer annealing to the $3^{\prime}$ end the ssDNA was coupled with its amine labelled $5^{\prime}$ end to the surface [11].

\section{Preparation of DNA Synthesis}

After gluing the coverslips to a mask containing six reaction vessels a mixture of dNTPs (unlabelled $3.3 \times$ $10^{-6} \mathrm{M}$, MBI Fermentas, Germany and $3.3 \times 10^{-7} \mathrm{M}$ Cy5-dCTP or Cy5-dUTP, Amersham Biosciences) and one unit of enzyme (Klenow fragment or Sequenase T7 polymerase, Cyscribe reverse transcriptase, Amersham Biosciences, unit defined by supplier) was dissolved in reaction buffer (purchased with the specific enzymes). After adding the dNTP mix the reaction was started by pipetting the enzyme.

\section{Fluorescence Detection}

In order to detect the incorporation of $\mathrm{Cy} 5$ into surface bound DNA in presence of high dye concentrations it is necessary to restrict the fluorescence detection volume to the interface as much as possible. We have developed an optical biosensor that detects the supercritical angle fluorescence (SAF), reducing the penetration of the detection volume into the solution to less than $100 \mathrm{~nm}[12,13]$. To vary the temperature of the experiments we used a homemade heating control.

\section{RESULTS}

The Cyscribe enzyme, which is a mutated MML-V reverse transcriptase, is in use to transcribe RNA into cDNA and integrate Cy5-dCTP. MML-V reverse transcriptase is known to feature polymerase activity. However we found, that dsDNA synthesis at the interface with Cyscribe does not take place at all, as we detected no increase of surface fluorescence. The exonuclease free Klenow fragment is widely used in biochemical applications for its high reliability. It has been shown that it is able to incorporate dyes into DNA [9]. The more recently developed T7 polymerase was claimed to be more efficient for the incorporation of dye-dNTPs.
To investigate the influence of the temperature on polymerase activity we measured the synthesis with the Klenow fragment at $25^{\circ} \mathrm{C}$ and $38^{\circ} \mathrm{C}$ and with the $\mathrm{T} 7$ polymerase at $25^{\circ} \mathrm{C}$ and $41^{\circ} \mathrm{C}$. Each reaction was repeated three times. The averaged fluorescence increases during dsDNA synthesis with Klenow and T7 are shown in Fig. 1a and $b$ respectively. In all shown figures the background signal was subtracted from the data and the start time was set to zero. In order to minimize photobleaching the intensity was gathered every $90 \mathrm{~s}$, the rest of the time the laser was blocked by means of a mechanical shutter. The velocities of the reactions are rather slow, as the rise of
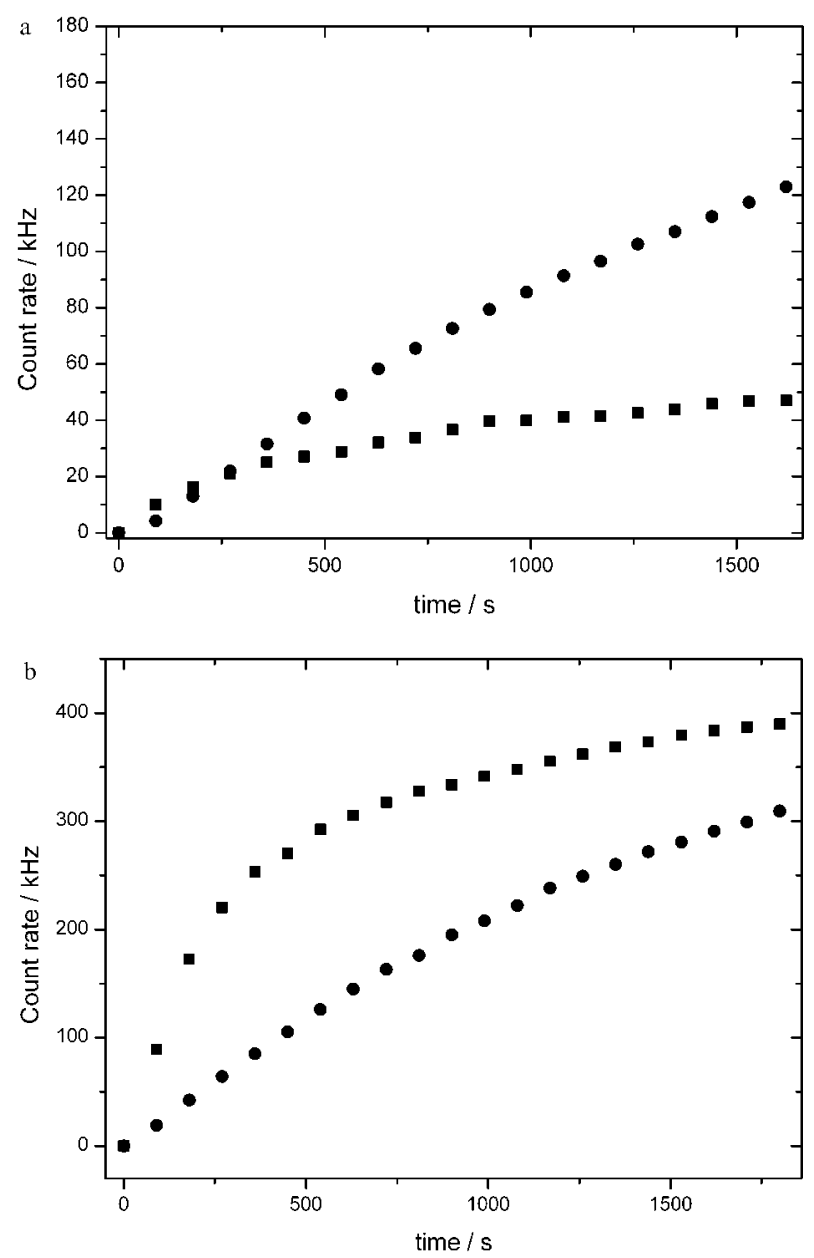

Fig. 1. a: Fluorescence signal vs. time during DNA strand synthesis. Reaction temperature comparison of $\mathrm{T} 7$ polymerases. Squares: Average measurement with $\mathrm{T} 7$ polymerase at $42^{\circ} \mathrm{C}$; Circle: Average measurement with $\mathrm{T} 7$ polymerase at room temperature. b: Fluorescence signal vs. time during DNA strand synthesis. Reaction temperature comparison of Klenow fragment (exonuclease free). Circle: single measurement with Klenow fragment at $38^{\circ} \mathrm{C}$; squares: Average measurement with Klenow fragment at room temperature. 
the fluorescence signal was not completed within $30 \mathrm{~min}$. Compared to their natural working conditions the situation for the enzymes is complicated by steric hindrances by the dye and the surface. Varying the temperature has significant influence upon the reaction kinetics. For both polymerases a higher activity was measured at room temperature. The Klenow fragment showed a higher reaction velocity at $25^{\circ} \mathrm{C}$, the yield of the product however was found to be nearly independent from temperature. The reaction yield as well as velocity of $\mathrm{T} 7$ polymerase is strongly decreased at increased the temperature. The explanation for this effect is, that the enzymes have a broad temperature intervall in which they are effective, but they are more stable at room temperature. Also enzymes degrade faster at higher temperature, so there exists an overlay of two processes.

A comparison of the two polymerases at $25^{\circ} \mathrm{C}$ is given at Fig. 2. Accordingly the Klenow fragment is more efficient in building up labelled dsDNA at the interface. Hence we used the Klenow fragment to study the influence of exchanging the dye labelled base. To incorporate Cy5dUTP we immobilized ssDNA containing three adenines and for Cy5-dCTP incorporation ssDNA containing three guanines. As shown in Fig. 3 the enzyme is bearly able to cope with the labelled uracile bases.

\section{DISCUSSION}

To date no polymerase/dye-dNTP combination is known, that approaches the incorporation rates of the en-

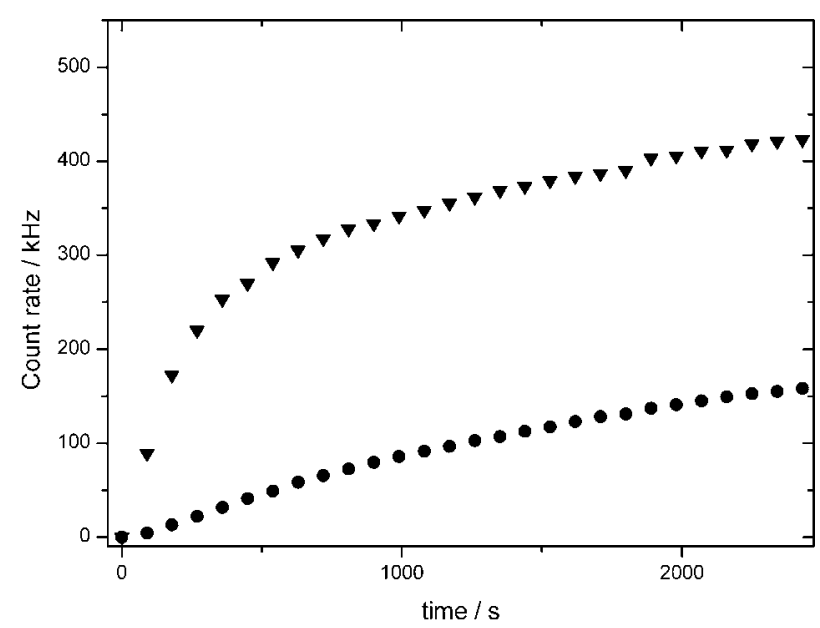

Fig. 2. Fluorescence signal vs. time during DNA strand synthesis at room temperature. Comparison of Klenow fragment and T7 polymerases. Triangles: Average of the measurement with Klenow (exonuclease free) fragment; circles: Average of the measurement with T7 polymerase.

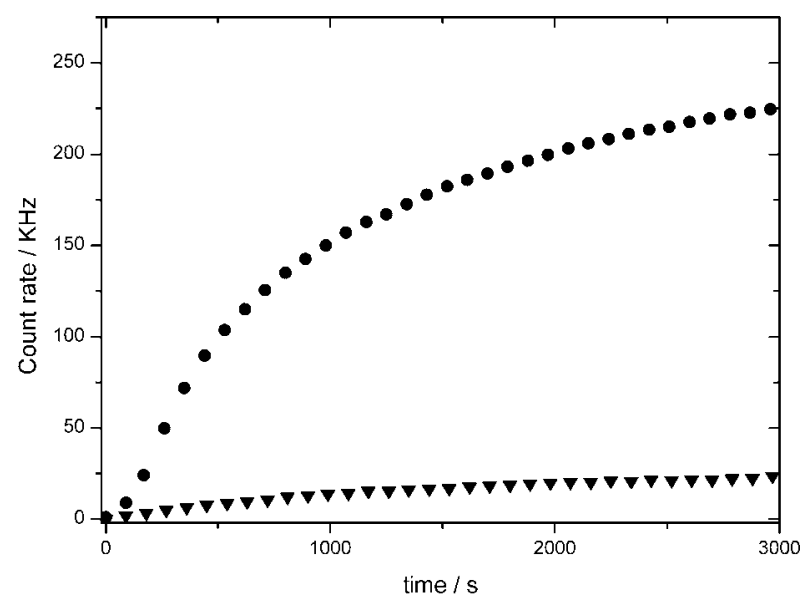

Fig. 3. Fluorescence signal vs. time during DNA strand synthesis. Comparison of dCTPs and dUTPs Circles: Average incorporation of $3 \mathrm{Cy} 5-$ dCTPs; triangles: Average incorporation of 3 Cy5-dUTPs.

zymes under natural conditions. For this reason the search and synthesis for polymerase-dye tagged dNTP systems is going on for maximizing the yield of incorporated labelled dNTPs and conclusively fast and reliable methods for proving the efficiency are essential $[14,15]$.

The collected data suggest that the best of the investigated dye-enzyme pairs for an accurate incorporation efficiency is the Klenow-fragment-Cy5-dCTP. The advantage of the developed biosensor lies in the easy and continuous collecting of the data. There is no need for further interference after adding of the reaction mixture and the kinetics of the whole reaction are measured and not just the endpoint signals. Besides measurement of the polymerase activity this setup also allows detection of Single Nucleotide Polymorphisms (SNPs) based i. e. on primer elongation. The next step for this setup is to reduce the background fluorescence by blocking the surface and increasing the quantum yield per incorporated dye [16,17].

\section{REFERENCES}

1. K. Mullis, F. Faloona, S. Scharf, R. Saiki, G. Horn, and H. Erlich (1986). Specific enzymatic amplification of DNA invitro-The polymerase chain-reaction. Cold Spring Harb. Sym. 51, 263-273.

2. F. Sanger, S. Nicklen, and A. R. Coulson (1977). DNA sequencing with chain-terminating inhibitors. Proc. Natl. Acad. Sci. U.S.A. 74(12), 5463-5467.

3. E. D. Hyman (1988). A new method of sequencing DNA. Anal. Biochem. 174(2), 423-436.

4. M. J. Levene, J. Korlach, S. W. Turner, M. Foquet, H. G. Craighead, and W. W. Webb (2003). Zero-mode waveguides for single-molecule analysis at high concentrations. Science 299(5607), 682-686.

5. L. T. C. Franca, E. Carrilho, and T. B. L. Kist (2002). A review of DNA sequencing techniques. Q. Rev. Biophys. 35(2), 169-200. 
6. M. Schena, R. A. Heller, T. P. Theriault, K. Konrad, E. Lachenmeier, and R. W. Davis (1998). Microarrays: Biotechnology's discovery platform for functional genomics. Trends Biotechnol. 16(7), 301306.

7. S. Brakmann (2001). Discovery of superior enzymes by directed molecular evolution. Chembiochem. 2(12), 865871.

8. H. Tveit and T. Kristensen (2001). Fluorescence-based DNA polymerase assay Anal. Biochem. 289(1), 96-98.

9. S. Brakmann and P. Nieckchen (2001). The large fragment of Escherichia coli DNA polymerase I can synthesize DNA exclusively from fluorescently labeled nucleotides. Chembiochem. 2(10), 773777.

10. A. Krieg, S. Laib, T. Ruckstuhl, and S. Seeger (2003). Real-time detection of nucleotide incorporation during complementary DNA strand synthesis. Chembiochem. 4(7), 589592.

11. N. Zammatteo, L. Jeanmart, S. Hamels, S. Courtois, P. Louette, L. Hevesi, and J. Remacle (2000). Comparison between different strategies of covalent attachment of DNA to glass surfaces to build DNA microarrays. Anal. Biochem. 280(1), 143-150.
12. T. Ruckstuhl, M. Rankl, and S. Seeger (2003). Highly sensitive biosensing using a supercritical angle fluorescence (SAF) instrument. Biosens. Bioelectron. 18(9), 1193-1199.

13. J. Enderlein, T. Ruckstuhl, and S. Seeger (1999). Highly efficient optical detection of surface-generated fluorescence. Appl. Optics 38(4), 724-732.

14. G. Giller, T. Tasara, B. Angerer, K. Muhlegger, M. Amacker, and H. Winter (2003). Incorporation of reporter moleculelabeled nucleotides by DNA polymerases. I. Chemical synthesis of various reporter group-labeled $2^{\prime}$-deoxyribonucleoside- $5^{\prime}$ triphosphates. Nucl. Acids Res. 31(10), 2630-2635.

15. T. Tasara, B. Angerer, M. Damond, H. Winter, S. Dorhofer, U. Hubscher, and M. Amacker (2003). Incorporation of reporter molecule-labeled nucleotides by DNA polymerases. II. High-density labeling of natural DNA. Nucl. Acids Res. 31(10), 2636-2646.

16. T. Scott, S. Smith, B. Windle, and A. Guiseppi-Elie (2003). Impact of surface chemistry and blocking strategies on DNA microarrays. Nucl. Acids Res. 31(16), e87.

17. J. Malicka, I. Gryczynski, B. P. Maliwal, J. Y. Fang, and J. R. Lakowicz (2003). Fluorescence spectral properties of cyanine dye labeled DNA near metallic silver particles. Biopolymers 72(2), 96-104. 